Jiménez Ruiz, M., Rodríguez Navarro, H., Sánchez Fuentes, S. \& Rodríguez Medina, J. (2018). Construcción del discurso en torno a la Educación Inclusiva. Revista Electrónica Interuniversitaria de Formación del Profesorado, 21(1), 185-217.

DOI: http://dx.doi.org/10.6018/reifop.21.1.305771

\title{
Construcción del discurso en torno a la Educación Inclusiva
}

\author{
María Jiménez Ruiz', Henar Rodríguez Navarro', Sergio Sánchez Fuentes², Jairo Rodríguez \\ Medina $^{1}$ \\ 'Universidad de Valladolid; ${ }^{2}$ Universidad Autónoma de Madrid
}

\section{Resumen}

En este trabajo se realiza un análisis cualitativo sobre los discursos de 85 profesionales en torno a la conceptualización de la Educación Inclusiva. Para ello, se usa la técnica del text mining para contabilizar la frecuencia de los términos utilizados unido a la categorización axial de los discursos. Posteriormente se reconstruye esta información mediante un marco de análisis. Los tres ámbitos están basados en la toma de decisión curricular de un docente. Todo ello con la intencionalidad de llegar a acuerdos teóricos en torno a este fenómeno y poder establecer puentes de conexión entre los postulados étics ofrecidos por la literatura y los producidos por los sujetos en la práctica de carácter émic. Concluimos el texto, por tanto, con una serie de postulados en torno a los que giran estos discursos y que condicionan de forma notable la práctica diaria de las escuelas.

\section{Palabras clave}

Educación inclusiva; profesores; cualitativa; text mining.

\section{Construction of the discourse on Inclusive Education}

\begin{abstract}
In this paper a qualitative analysis is made on the speeches of 85 professionals around the conceptualization of Inclusive Education. To do this, the text mining technique is used to account for the frequency of the terms used together with the axial categorization of the speeches. This information is then reconstructed through a framework of analysis. The three areas are based on the curricular decision-making of a teacher. All this with the intention of arriving at theoretical agreements around this phenomenon and being able to
\end{abstract}


establish bridges of connection between the etics postulates offered by the literature and those produced by the subjects in the practice of emic character. We conclude the text, therefore, with a series of postulates around those that revolve these speeches and that condition of remarkable form the daily practice of the schools.

\section{Keywords}

Inclusive education; teachers; qualitative; text mining.

\section{Introducción}

Un reto creciente para la educación de todos los países, reside en ofrecer una educación inclusiva y de calidad. Además de ser un derecho humano fundamental, es la base para lograr una cohesión social (UNESCO 1994, 2005). En los últimos años la educación inclusiva ha recibido un impulso en muchos sistemas educativos (Mitchel, 2005). Incluso algunos autores (Parrilla y Sierra, 2015) más actuales afirman que la propia investigación tiene que tornar hacia aspectos que tengan en cuenta la inclusividad como eje en la investigación en ciencias sociales.

A partir de la crítica de la educación especial inspirada en las clasificaciones de estudiantes por supuestos defectos, tal y como denuncian diferentes instituciones (Department for Education and Skills, 2001; Commision for Racial Equality, 2001; Disability Rights Commission, 2007), se ha ampliado el debate científico hasta confluir en el concepto de educación inclusiva o educación para todos (Ainscow, Farrell y Tweddle, 2000; Dyson y Millward, 2000; Echeíta y Ainscow, 2011), produciéndose, a partir de la Conferencia de Salamanca (Echeíta y Verdugo, 2004), un giro terminológico en el cual se pasó de hablar de integración a inclusión, conceptualizando el término desde enfoques educativos más fructíferos, que se alejaban de las teorías del déficit y se centraban en la eficacia de escuelas inclusivas para todos (Sebba y Ainscow, 1996; Farrell, 2000a; Vislie, 2003). Trabajos más recientes como el presentado por Bunch (2015), o el descrito por De la Rosa (2017), hablan de la necesidad de conceptualizar la educación inclusiva en las sociedades contemporáneas haciendo partícipes a los propios agentes del cambio.

Siguiendo la investigación internacional (Ainscow, 2001; Ainscow, Booth, y Dyson, 2006) y con el propósito de ofrecer un marco de referencia con el que realizar un análisis teórico posterior de los modelos inclusivos emergentes a nivel internacional, nos encontramos con cuatro esferas que interactúan entre sí: políticas; conceptos; estructuras; sistemas y prácticas (Ainscow, et al., 2006) y que en función de cómo sean esas interacciones, estarán determinando la marcha de la inclusión educativa, que a su vez se operativizan con tres variables relevantes a nivel escolar: presencia, aprendizaje y participación.

Con presencia se refieren a los lugares en los cuales están escolarizados los estudiantes. Por progreso se entiende que el centro adopta las medidas para proporcionar experiencias de calidad a todos los estudiantes para optimizar el rendimiento escolar. Y la variable participación se concreta en el deber de reconocer y apreciar la identidad de cada estudiante y la preocupación por su bienestar personal (autoestima, compañerismo, ausencia de exclusión) (Echeíta, Verdugo, Sandoval, Calvo, y González-Gil, 2009).

Los discursos y los imaginarios sobre la educación inclusiva se han estudiado hasta el momento a través de metodologías de corte etnometodológico donde el actor es considerado como parte activa del proceso de construcción de sus discursos y sus prácticas. 
De la perspectiva sistémica-estructural defendida por autores como Pearson, donde el individuo era considerado un "idiota cultural", es decir, como un agente que actúa únicamente con las normas que le son impuestas, se abrió paso en años posteriores, a visiones de investigación subjetivas a partir de los estudios sobre "desviaciones sociales" de Harold Garfinkel y la etnometodología derivada de Weber donde los métodos de investigación implican interacción entre el investigador y grupos sociales específicos. Las técnicas usadas en este último enfoque desde el que planteamos nuestro estudio (entrevistas y grupos de discusión) permiten analizar los discursos de los profesionales de la educación producidos en tres niveles de profundidad (el metateórico, el teórico y el técnico). A continuación, explicamos dicho marco de análisis con el que construimos las categorías de análisis y la teoría que de ellas se desprende.

Marco de análisis con un triple nivel de ámbitos desde los que tomar decisiones en la práctica docente

Analizamos el discurso y los imaginarios que de ellos se derivan, a partir de los tres ámbitos desde donde entender la decisión docente (Cascante, 1995; Carr, y Kemmis, 1998). Tratamos de identificar, por tanto, las ideas, creencias, conocimientos comunes y realidad diaria estableciendo conexiones entre los diferentes niveles de análisis que influyen a la hora de formar imaginarios sociales sobre la Inclusión Educativa (en este caso) y para tomar decisiones prácticas en el día a día.

El marco de análisis consiste en ir describiendo los ámbitos que influyen en la decisión del docente (Cascante, 1995; Carr y Kemmis, 1998). Cada uno de estos ámbitos corresponde a un nivel de profundidad en el discurso y no pueden considerarse de forma aislada, sino que unos están influenciados en otros.

A.- En el nivel más profundo (si habláramos de un iceberg constituiría la raíz más profunda del mismo), se encuentra el nivel metateórico, los discursos en este nivel se nutren de las perspectivas sociológicas que han ido sucediéndose en la historia de las ciencias sociales y que han determinado de una forma u otra de conceptualizar la realidad social y a su vez las ciencias de la educación. En este sentido nos encontramos con las teorías sistémicas, las subjetivas y las duales. A las primeras, estructuralistas (Althusser, 1970; Bourdieu y Passeron, 1970) se les atribuyen leyes determinantes de sus estructuras y actuaciones, manipuladas por una minoría que domina el funcionamiento político de la población. Entienden la estructura, como elemento del sistema que asegura cierta estabilidad entre el sistema y el medio. Tiene que ver con perspectivas del currículum, dominado por el discurso de la autoridad política, con poca permeabilidad a los cambios sociales y con itinerarios definidos acordes con lo que marca la estructura legislativa del momento. Las segundas teorías, subjetivas, parten de una concepción de la sociedad construida por las acciones de las personas. El estudio de la sociedad y de la educación desde esta óptica está construido desde las voces de los sujetos. El currículum desde esta perspectiva es entendido desde las individualidades y mundos internos de cada sujeto. $\mathrm{Y}$ las terceras teorías, denominadas duales (Beck, Lash y Giddens, 1997; Giddens, 1998; Habermas, 2001a, 2001b) en ellas estructura y acción del individuo interactúan entre sí para construir los imaginarios sociales. Desde este último enfoque, los escolares y los miembros de la comunidad escolar (profesores, familias y agentes sociales) interactúan entre sí, teniendo en cuenta las estructuras de la institución y aunque no pueden cambiar algunas cosas, si pueden usarlas manipulándolas en interacción.

B.- Un segundo ámbito de construcción del discurso y de la práctica, está constituido por la conceptualización educativa, es decir, por las perspectivas desde donde enfocar el trabajo docente, éstos pueden ser de corte objetivista, constructivista o comunicativa. La primera 
concepción se desarrolló en un contexto social denominado la sociedad industrial donde la realidad es entendida de forma independiente a los individuos que la utilizan y el aprendizaje se basaba en el contenido emitido por el profesor al alumnado mediante un proceso de asimilación que desemboca en la repetición de la información. Este enfoque fue traducido en el terreno escolar y en el nivel técnico de este marco de análisis, con la aplicación de diferentes técnicas de corte conductista, de transmisión del conocimiento de forma magistral, de énfasis de trabajos relacionados con la memoria, con la acumulación de conocimientos, etc. En la segunda mitad del siglo XX, las concepciones educativas iban sufriendo los mismos cambios que los que iban sucediéndose en la sociedad. Las teorías objetivas que explicamos en el ámbito anterior, van consolidando maneras de entender la realidad de forma subjetiva (Berger y Luckmann, 1968), en las que los sujetos y los grupos son considerados agentes sociales y se establece que la realidad social es una construcción humana que depende de los significados que le damos las personas. La psicología cognitiva pasaba a dar una explicación constructiva del funcionamiento diferente a la objetivista, los sujetos intervienen en la construcción de la realidad y cada sujeto elabora sus propias tipificaciones o esquemas de conocimiento. Para el aprendizaje supuso el cambio de la asimilación a la construcción repercutiendo en el rol del alumnado que pasa a ser el elemento principal del aprendizaje y sujeto activo que construye su propio conocimiento mediante la relación significativa de los nuevos conocimientos con los previamente adquiridos. El profesorado constituye un andamiaje (Wood, Bruner y Ross, 1976) facilitador de ayudas en función de los diferentes niveles de conocimiento del alumnado. La concepción comunicativa de aprendizaje, tercera concepción educativa de este ámbito teórico, crece en el seno de una sociedad de la información, donde sistemas y relaciones personales coexisten (Giddens, 1995; Habermas, 2001a). Esta concepción tiene su base en la perspectiva dialógica de la realidad, descrita con el nombre de "giro dialógico de las sociedades" (Flecha, Gómez, y Puigvert, 2001)

C.- Por último, el tercer ámbito que da origen a unos discursos y prácticas, está constituido por los aspectos más concretos de la labor diaria (las relaciones, las actividades que se realizan, los materiales usados, la organización de las aulas, etc). Estas acciones están condicionadas por los ámbitos anteriores, de tal modo que una concepción educativa objetivista, bajo la influencia de corrientes conductistas será reflejada con metodologías basadas en la transmisión de contenidos a los estudiantes, como la lección magistral. Desde la perspectiva constructiva, las acciones educativas estarán vinculadas a propuestas pensadas en la individualidad del alumnado, tales como la experimentación, la adaptación a las necesidades de cada sujeto vinculada a la etapa de desarrollo en la que se encuentra el individuo (Piaget y Inhelder 1977). Se otorga por tanto protagonismo a la cognición individual que pasa a un segundo plano la influencia del contexto social de aprendizaje. El último enfoque sociocultural (Freire, 1970; Rogoff, 1993; Vygotsky, 1996; Bruner, 2000; Wells, 2001), está ligado a experiencias escolares en torno al diálogo, la colaboración y la participación de la comunidad, propuestas prácticas desde este enfoque son, el aprendizaje dialógico y el aprendizaje colaborativo y actividades basadas en la interacción entre iguales. Hay un cambio de rumbo de la adaptación a los conocimientos previos hacia la transformación de los niveles de partida vinculados al contexto social y cultural (Vygotsky, 1995, 1996).

Estos tres ámbitos, podrían aparecer de forma independiente, sin embargo, están íntimamente influenciados entre sí. Este marco nos ayuda a analizar los discursos de profesionales de la educación mediante la relación entre lo que dicen que hacen y las conceptualizaciones educativas y epistemológicas que hay de fondo. 
En este artículo vamos a describir los discursos de varios grupos de discusión y el análisis de los mismos siguiendo el marco descrito anteriormente sobre el triple ámbito de decisión docente. Pretendemos por tanto explicar sus discursos, analizar las concepciones y epistemologías que hay de fondo y extraer cuáles son los principales imaginarios colectivos que facilitan y dificultan la puesta en marcha de actuaciones educativas inclusivas.

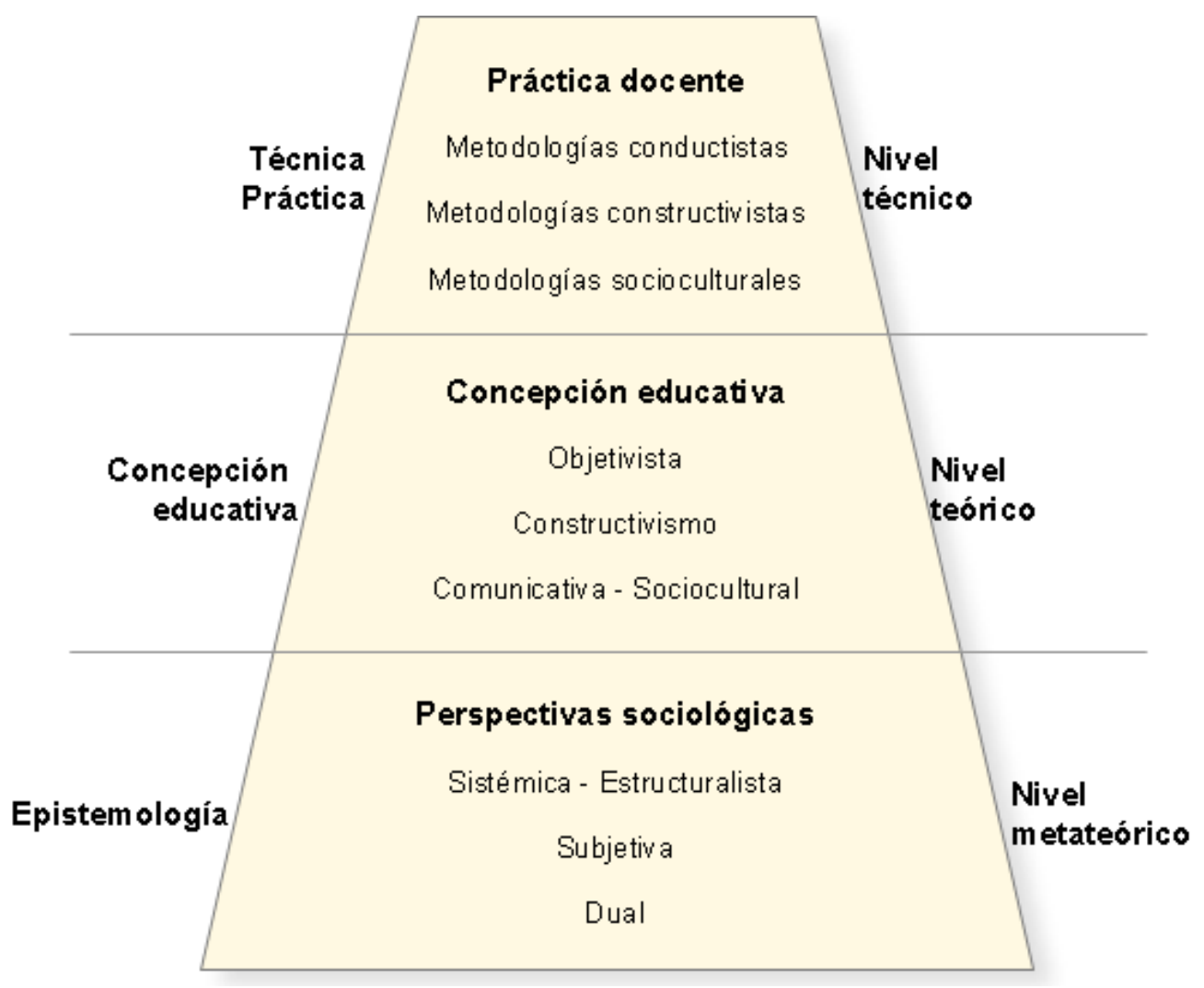

Figura 1. Triple ámbito de decisión docente

\section{Método}

\section{Participantes}

Los participantes se dividieron en dos subgrupos. Se les pidió que realizaran una definición de Educación Inclusiva y un análisis cualitativo de los ítems a partir de la pregunta, ¿en qué medida considera que se ajustan los ítems a la realidad educativa que conoce? Participaron 12 personas en cada subgrupo, uno formado por directores de centros educativos y otro por profesores de Educación Compensatoria, Pedagogía Terapéutica, Audición y Lenguaje y tutores de aula guiados por un moderador experto, encargado de encauzar las discusiones y opiniones para conocer cómo pensaban los participantes respecto a los ítems de la escala de Inclusión Educativa.

\section{Instrumento}

Dentro del proceso de elaboración de una escala para evaluar la calidad educativa en las aulas desde la perspectiva inclusiva, Escala Acoge, se realizó un Grupo de discusión (Merton y Kendall, 1946; Krueger, 1991; Krueger, y Casey, 2000), donde participaron 24 profesionales españoles. 


\section{Procedimiento}

Se estableció un contacto previo telefónico y escrito con los representantes de los profesionales de los centros escolares implicados en la investigación. Una vez aceptaron colaborar, se pidió a los participantes que: (a) realizaran una lectura de todos los ítems, (b) remitieran los ítems seleccionados como más importantes para evaluar la calidad de la inclusión en las aulas (c) invitaran a dos personas de sus centros acudir al grupo de discusión en la Universidad.

Las respuestas de los participantes guiaron la selección de los ítems entre aquellos que fueron calificados como más importantes y menos importantes. Estos ítems sirvieron de hilo conductor en la discusión llevada a cabo en los grupos.

Iniciamos las sesiones con un tiempo de reflexión en el que les pedimos que escribiesen en dos frases, lo que cada uno entendía por Educación Inclusiva. Tras la lectura y comentarios al respecto, el moderador elaboró una definición consensuada por el grupo, de Educación Inclusiva. Con posterioridad procedimos a leer uno a uno los ítems considerados más importantes en el análisis, es decir, aquellos que obtuvieron una puntuación por encima de .2 (en una escala teórica de $-1 \mathrm{a}+1$ ) según la valoración conjunta realizada. Cada uno de estos ítems seleccionados fue sometido a las siguientes preguntas para su discusión:

- ¿Por qué creéis que este ítem refleja vuestra definición de Educación Inclusiva?

- ¿Cómo creéis que se formularía mejor para que fuese observable y evaluable?

- ¿Pensáis que falta algún ítem para medir esa dimensión?

Para finalizar la sesión les pedimos que sugiriesen pautas de intervención adecuadas desde el punto de vista de la Educación Inclusiva.

\section{Análisis de datos}

Para trabajar con todos los datos se ha utilizado el programa de análisis cualitativo Nud*ist VIVO 8.0 (Herreras, 2004), que permite disponer y transformar los datos mediante el recuento de unidades de texto adjudicadas a los diferentes nudos o categorías. Esta reducción de datos y su separación en categorías posibilita la identificación y clasificación de los elementos para análisis de forma relevante y significativa.

Para ello, se ha partido de un sistema de categorías previamente establecido que mostramos en la Tabla 1.

Tabla 1.

Categorías análisis

\begin{tabular}{lccc}
\hline CONCNICA/PRÁCTICA & M. Conductistas & M. Constructivistas & SOCIOCONSTRUCTIVISMO \\
\hline $\begin{array}{l}\text { CONCEPCIÓN } \\
\text { EDUCATIVA }\end{array}$ & Objetivista & Constructivista & $\begin{array}{c}\text { Comunicativa- } \\
\text { Sociocultural }\end{array}$ \\
\hline EPISTEMOLOGÍA & $\begin{array}{c}\text { Sistémica- } \\
\text { Estructuralista }\end{array}$ & Subjetiva & Dual \\
\hline
\end{tabular}

Realizamos también un análisis cuantitativo mediante la técnica del test-mining que nos permitió conocer qué palabras componen el discurso sobre educación inclusiva de los profesionales que formaron parte de los grupos de discusión. 


\section{Resultados}

Describimos los resultados obtenidos en el grupo de discusión realizado con los profesionales de la educación en la medida que han contribuido a mejorar el constructo teórico de la escala ACOGE. En primer lugar, hacemos un breve análisis de contenido útil para entender los puntos de partida de cada profesional respecto a esta temática.

Todas las definiciones que los profesionales realizan sobre Educación Inclusiva, han reflejado el significado de la variable "Presencia". De los 24 profesionales, 15 han incluido también la variable "participación", siendo directores de centros la mayoría de los que daban más importancia a esta idea participativa y comunitaria (11 de 12). Sin embargo, 8 de los 12 profesores tutores, resaltaban en sus construcciones teóricas la idea de progreso y menos la de participación. Deduciendo, por tanto, que cada rol profesional prioriza más una variable u otra de la Educación Inclusiva en función (entre otras cosas) de la acción profesional con la que se encuentran en el día a día. Los resultados los exponemos a continuación en la Tabla 2.

Tabla 2.

Resultados las definiciones de Educación Inclusiva aportadas por los profesionales

\begin{tabular}{lcccc}
\hline & Presencia & Progreso & Participación & Total \\
\hline Directores & 12 & 1 & 11 & 12 \\
\hline Profesores & 12 & 8 & 4 & 12 \\
\hline Total & 24 & 9 & 15 & 24 \\
\hline
\end{tabular}

Del análisis cuantitativo realizado mediante test-minig obtenemos las diez palabras más citadas con sus frecuencias (Tabla 3) y en la Figura 1 aquellos términos que adquieren una relevancia especial en el análisis de los discursos por su reiteración.

Tabla 3.

Frecuencia de las diez palabras más referenciadas

\begin{tabular}{lr}
\hline \multicolumn{1}{c}{ PALABRA } & FRECUENCIA \\
\hline Alumnado & 301 \\
Inclusión & 152 \\
Educación & 111 \\
Aula & 94 \\
Necesidad & 81 \\
$\quad$ Profesorado & 75 \\
Evaluación & 64 \\
Trabajo & 59 \\
Programación & 58 \\
\hline
\end{tabular}




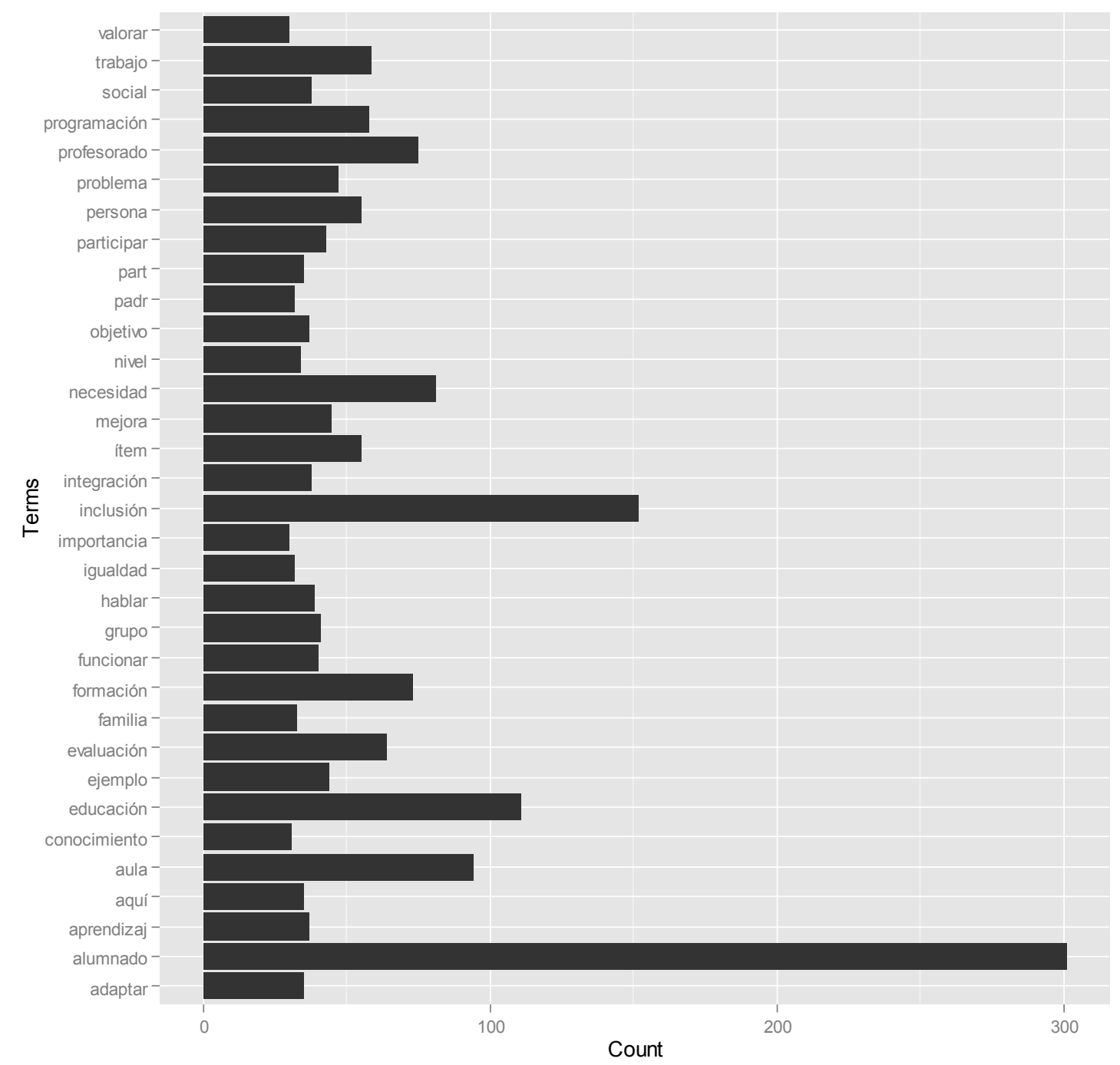

Figura 2. Palabras reiteradas en el discurso del profesorado

En el análisis de clusters realizado obtenemos el siguiente esquema (Figura 3)

Centramos el siguiente análisis en el número de referencias existentes en cada grupo de discusión, relativas a cada una de las categorías, descritas en la Tabla 4. Estos datos reflejan cómo el discurso de los profesionales de la educación al hablar de Educación Inclusiva está transitando desde una perspectiva skinneriana con 17 referencias en el grupo de discusión de docentes pertenecientes a equipos directivos y 26 en el grupo de discusión del profesorado, pasando por una perspectiva más Piagetiana con 27 y 85 referencias respectivamente, que evoluciona hacia otra más vygotskyana, en las que el contexto sociocultural toma protagonismo en el aprendizaje con 80 reseñas de los directores y 131 del profesorado.

Se analizan a continuación cada una de las perspectivas objeto de interés puntualizando cuales son las referencias aludidas por los profesionales participantes en los grupos de discusión. 


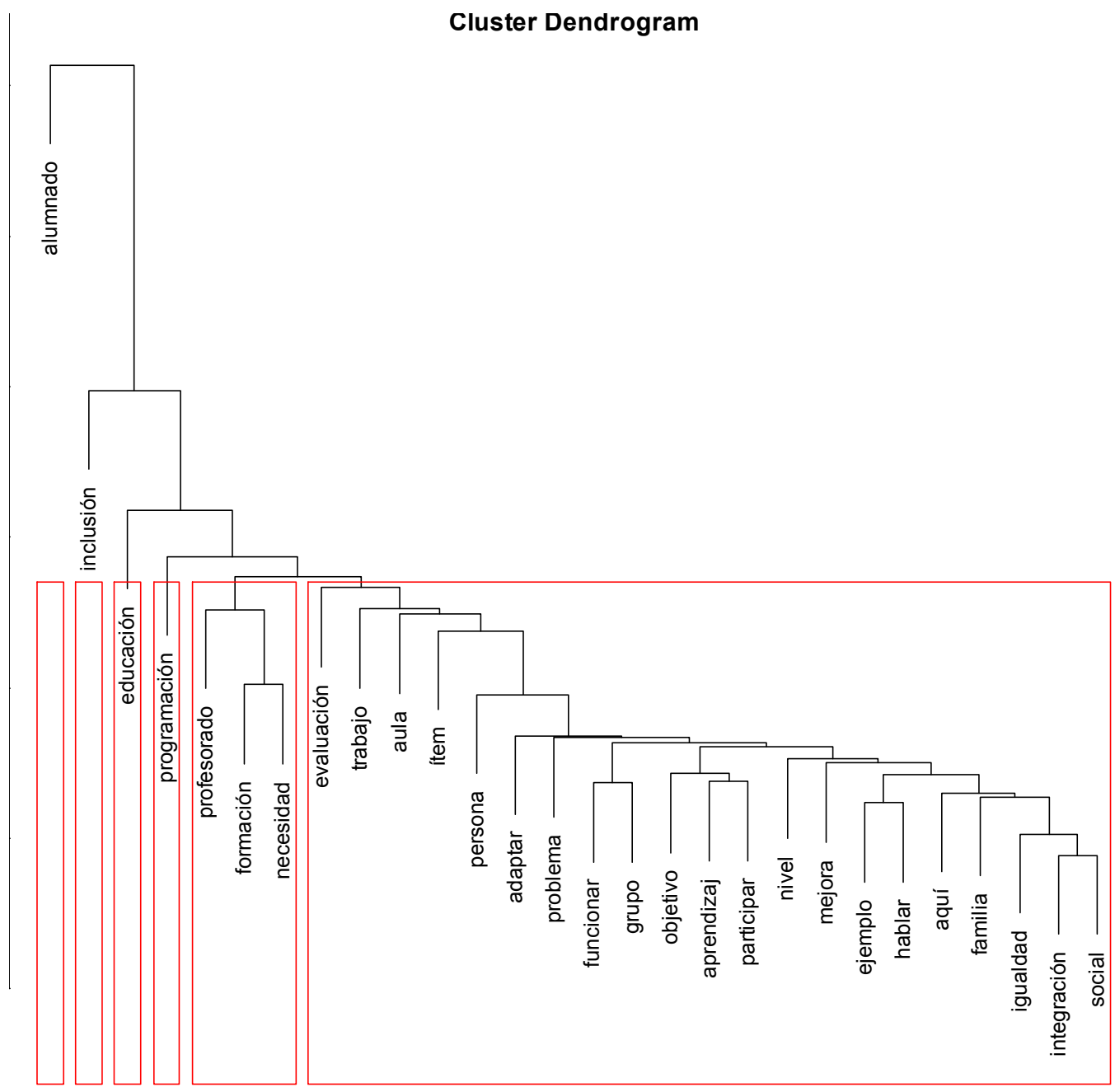

Figura 3. Esquema clusters

Tabla 4.

Número de referencias existentes según categorías de análisis

\begin{tabular}{clccc}
\hline & & $\begin{array}{c}\text { GD. Equipo } \\
\text { directivo }\end{array}$ & $\begin{array}{c}\text { GD. } \\
\text { Profesorado }\end{array}$ & Total \\
\hline \multirow{2}{*}{ TÉCNICA } & Conductista & 2 & 1 & 3 \\
& Constructivista & 1 & 11 & 12 \\
& Sociocultural & 1 & 28 & 29 \\
\hline \multirow{2}{*}{ CONCEPCIÓN } & Objetivista & 8 & 24 & 32 \\
EDUCATIVA & Constructivista & 14 & 63 & 77 \\
\cline { 2 - 5 } & Comunicativa-sociocultural & 26 & 63 & 89 \\
\hline \multirow{2}{*}{ EPISTEMOLOGÍA } & Sistémica-Estructuralista & 7 & 1 & 8 \\
& Subjetivista & 12 & 11 & 23 \\
& Dual & 53 & 40 & 93 \\
\hline
\end{tabular}

Las menciones realizadas acordes con una perspectiva conductista hacen referencia a la utilización del libro de texto: argumentan que es más cómodo, requiere menos esfuerzo, es más fácil su utilización para el profesorado que trabajar por proyectos y les aporta una mayor seguridad en su labor docente. También exponen prejuicios e ignorancia por parte de las familias cuando se utilizan otras metodologías: 
$<$ Elementos internos\directores\Transcripción Grupo discusión directores $>$ $\$ 2$ referencias codificadas [Cobertura $0,26 \%$ ]

Referencia 1 - Cobertura $0,13 \%$

Todos sabemos delante de un libro que es lo que tenemos que hacer,

Referencia 2 - Cobertura $0,12 \%$

pero es que en nuestra educación está arraigado, es la biblia,

Referencia 2 - Cobertura 0,32\%

Es mejor sentarse en una mesa y leer un libro, que preparar una actividad en la que unos ayuden a otros, en la que tengas que estar de pie, moverte por el aula, etc

Referencia 3 - Cobertura 0,18\%

Eso sería mucho más trabajo y hay mucho personal que ahora mismo no está dispuesto a eso.

Referencia 7 - Cobertura $0,24 \%$

aspectos negativos diría que hay aptitudes negativas e ignorancia en las familias y en los profesores, hay prejuicios.

$\leq$ Elementos internos \Profesores $\backslash$ Transcripción grupo de discusión profesores $>-\S 1$ referencia codificada [Cobertura $0,14 \%$ ]

Referencia 1 - Cobertura $0,14 \%$

Es un trabajo durísimo trabajar por proyectos, es mucho más fácil coger los libros y se acabó.

Figura 4. Primer análisis de los resultados obtenidos en el estudio

$\leq$ Elementos internos\directores\Transcripción Grupo discusión directores $>$ $\$ 8$ referencias codificadas [Cobertura 2,02\%]

Referencia 1 - Cobertura 0,24\%

Pero bueno, tú haces lo que puedes y hasta donde puedes. Habrá chicos que te captan todo, $y$ otros que te captan una gotita.

Referencia 4 - Cobertura 0,43\%

Si no sabemos hacer una adaptación curricular, o no sabemos detectar en una clase que niños necesitan ciertas cosas o no sabemos establecer niveles de conocimiento o los sistemas de aprendizaje, no estamos haciendo nada

$\leq$ Elementos internos \Profesores\Transcripción grupo de discusión profesores $>-\S 23$ referencias codificadas [Cobertura 4,43\%]

Referencia 2 - Cobertura 0,09\%

Y si no le conoces, yo no tengo porque conocer a los alumnos.

Referencia 32 - Cobertura $0,14 \%$

adaptación curricular que la hacemos no el tutor si no normalmente los profesores de apoyo.

Figura 5. Segundo análisis de los resultados obtenidos en el estudio 
Cuando hacen alusión a las adaptaciones curriculares, manifiestan dificultad para detectar diferentes necesidades, resignándose a hacer lo que cada maestro puede limitando a cada alumno en función de lo que sea capaz de captar. Establecen diferentes niveles de conocimiento sin tener en cuenta los aprendizajes previos.

En cuanto a las programaciones opinan que la administración otorga muy poco margen de flexibilidad para adaptar objetivos y contenidos. Afirman que programan para los grupos completos, no teniendo en cuenta a cada individuo. Uno de los motivos que argumentan es que las programaciones se hacen en septiembre/octubre cuando aún no tienen un conocimiento profundo del alumnado.

$\leq$ Elementos internos \Profesores\Transcripción grupo de discusión profesores $>-\S 23$ referencias codificadas [Cobertura 4,43\%]

Referencia 3 - Cobertura 0,19\%

Yo insisto, no sé a qué altura del curso hacéis programación o hacéis las ACS pero yo las hago en septiembre o en octubre

Referencia 5 - Cobertura 0,32\%

Pero hablando del punto de la programación, yo programo el curso escolar y cuando yo distribuyo los contenidos, las unidades didácticas, que tipo de actividades van en cada momento es en septiembre o en octubre

Referencia 7 - Cobertura 0,44\%

Precisamente por lo que tú has dicho que tú no programas para un niño si no que programas para el grupo completo en el momento que haces una programación para 25 no son los conocimientos previos de los 25 sino de la mayoría de esos 25 entonces a mí me parece importante pero no relevante.

Referencia 10 - Cobertura $0,52 \%$

que realmente adaptes los contenidos en función de esos conocimientos previos porque realmente tú lo haces en función de los conocimientos previos de la mayoría de la clase, no de cada uno de la clase porque hay niños que van a quedar por encima de sus conocimientos previos y niños que van a quedar por debajo de sus conocimientos previos.

$\leq$ Elementos internosldirectores\Transcripción Grupo discusión directores $>$ $\$ 8$ referencias codificadas [Cobertura $2,02 \%$ ]

Referencia 7 - Cobertura 0,26\%

la administración lo da todo marcado: objetivos, contenidos, horas de aprendizaje, etc. Entonces hay muy poco margen de maniobra.

Referencia 8 - Cobertura $0,11 \%$

Falta flexibilidad en la programación y en la realización

Figura 6. Tercer análisis de los resultados obtenidos en el estudio

Otro aspecto que mencionan es el tema de las evaluaciones, centradas en una evaluación sumativa final donde no se refleja ningún tipo de diferencia ni consideración en función de las características individuales del alumnado. Aluden a que las familias exigen resultados numéricos y genera conflicto entre éstas la posibilidad de algún tipo de evaluación 
adaptada. No ven adecuado que pueda existir una evaluación entre compañeros en la profesión, no admitiendo de esta manera ningún tipo de crítica constructiva.

$\leq$ Elementos internos ldirectores $\backslash$ Transcripción Grupo discusión directores $>$ $\$ 8$ referencias codificadas [Cobertura $2,02 \%$ ]

Referencia 5 - Cobertura $0,27 \%$

A los padres se les llena la boca, hablando de inclusión y de planteamientos, pero a la hora de la verdad no es así, y te exigen resultados

Referencia 6 - Cobertura $0,20 \%$

a la hora de la verdad lo único que miran son las notas de sus hijos y te van a pedir responsabilidades

$\leq$ Elementos internos $\backslash$ Profesores $\backslash$ Pautas de intervención. Profes $>-\$ 1$ referencia codificada [Cobertura 2,08\%]

Referencia 13 - Cobertura $0,11 \%$

al estudiante lo que le damos es una palabra final en torno a su evaluación

Referencia 14 - Cobertura 0,32\%

primaria y secundaria al final es una nota, así no le permite saber a cada uno en que aspecto tiene que crecer y en qué aspectos va sobrado si no que lo que se está haciendo es calificar el trabajo hasta el momento

Referencia 15 - Cobertura 0,15\%

Si tú preguntas a un niño, que es evaluación, estoy seguro que el $80 \%$ te saca el boletín de notas.

Referencia 18 - Cobertura 0,09\%

A mí me crea más problemas con los padres que con los niños

Referencia 23 - Cobertura 0,10\%

las sugerencias de mis compañeros más que una crítica constructiva.

Figura 7. Cuarto análisis de los resultados obtenidos en el estudio

En general manifiestan la necesidad de tener un mayor número de profesionales así como un cambio de mentalidad en la que se dé más importancia a la formación inicial y permanente del profesorado, aspecto no tenido en cuenta en las diferentes reformas acontecidas.

Se aprecia como en el discurso hay un incremento de alusiones con respecto a la perspectiva sistémica anteriormente analizada, a aspectos técnicos y metodológicos que encuadran con una concepción educativa de corte constructivista relacionada con una base sociológica subjetivista. Algunas de estas referencias son expuestas a continuación.

El libro de texto se considera una herramienta más, no de uso exclusivo; comienzan a hablar de la utilización de diferentes metodologías específicas acordes con una atención más individualizada que parta de los conocimientos previos. Entre las nuevas metodologías apuntan el trabajo en grupo e introducen la consideración del profesor y el aula de apoyo para aquellos alumnos con necesidades específicas. 
$\leq$ Elementos internos\directores\Transcripción Grupo discusión directores $>$ $\$ 7$ referencias codificadas [Cobertura 1,61\%]

Referencia 1 - Cobertura $0,40 \%$

hablamos de personal que atiende, de profesores-tutores con una formación y demás, pero si el medio es mi colegio es muy difícil llevar a cabo la educación inclusiva por el personal del que disponemos.

Referencia 2 - Cobertura $0,24 \%$

a veces nos cuesta a los propios docentes ese tipo de trabajos, no son solo los recursos, sino un cambio de mentalidad.

Referencia 3 - Cobertura $0,12 \%$

el problema también somos nosotros los propios profesionales.

Referencia 4 - Cobertura $0,14 \%$

Muchas veces en los colegios podemos tener la voluntad pero no sabemos

Referencia 5 - Cobertura $0,22 \%$

Mis hijos están estudiando magisterio ahora y tampoco sabrían trabajar en una sociedad inclusiva el día de mañana.

Referencia 6 - Cobertura $0,26 \%$

Ninguna de todas las reformas que ha habido, ha ido dirigida al origen de todo, que es nuestra formación, a reformar al profesorado

$\leq$ Elementos internos $\backslash$ Profesores $\backslash$ Transcripción grupo de discusión profesores $>-\S 1$ referencia codificada [Cobertura $0,06 \%$ ]

Referencia 1 - Cobertura 0,06\%

la crítica es siempre algo negativo.

Figura 8. Quinto análisis de los resultados obtenidos en el estudio

$\leq$ Elementos internos\directores\Transcripción Grupo discusión directores > $\$ 10$ referencias codificadas [Cobertura $2,31 \%$ ]

Referencia 10 - Cobertura $0,13 \%$

El libro de texto tiene que ser una herramienta más del profesorado,

$\leq$ Elementos internos\directores\Transcripción Grupo discusión directores $>$ $\$ 1$ referencia codificada [Cobertura $0,25 \%]$

Referencia 1 - Cobertura 0,25\%

Yo creo que el libro de texto no está bien situado por muchas cosas que hemos analizado aquí hoy: formación, utilización, tiempo.

$\leq$ Elementos internos $\backslash$ Profesores $\backslash$ Definiciones EI. Profes $>-\S 1$ referencia codificada [Cobertura $0,89 \%$ ]

Referencia 1 - Cobertura $0,89 \%$

el trabajo en grupo, la socialización entre unos y otros, coordinación, etc...

$\leq$ Elementos internos\Profesores\Transcripción grupo de discusión profesores $>-\$ 42$ referencias codificadas [Cobertura $8,04 \%$ ]

Referencia 6 - Cobertura $0,27 \%$

También depende de la metodología que utilices porque si tú trabajas una metodología constructivista tienes que partir de los conocimientos previos, no salen las cosas del libro,

Figura 9. Sexto análisis de los resultados obtenidos en el estudio 
Se percibe un aumento de expectativas por parte del profesorado hacia todo el alumnado, Consideran la necesidad de partir de unos objetivos generales comunes a todos y unos objetivos específicos diferentes en función de sus capacidades individuales. En coherencia con esta idea organizan actividades comunes con ciertas adaptaciones en función de las limitaciones. Aun así, se sigue hablando de realizar modificaciones en la programación en función de cómo evoluciona el grupo, no los individuos. La perspectiva de la evaluación también sufre cambios referidos a la necesidad de establecer una evaluación inicial del alumnado y una evaluación procesual de los aprendizajes, restando importancia a la evaluación exclusiva de resultados. Utilizan nuevas técnicas como la autoevaluación y el análisis de resultados con el propio alumnado, con la finalidad de hacerles conscientes de sus aprendizajes.

$\leq$ Elementos internos \directores\Transcripción Grupo discusión directores $>$ $\$ 10$ referencias codificadas [Cobertura $2,31 \%$ ]

Referencia 1 - Cobertura $0,19 \%$

objetivos educativos comunes pero adaptados a capacidades diferentes o potencialidades diferentes.

Referencia 2 - Cobertura $0,18 \%$

Puedes poner unos objetivos más generales, aunque alguno los tuviese más particulares

Referencia 4 - Cobertura $0,25 \%$

Yo lo que creo es que el enunciado debe de ser global, y el proceso o camino que lleva cada uno es donde está la diferencia.

$\leq$ Elementos internosldirectores $\backslash$ Definiciones EI directores $>-\$ 4$ referencias codificadas [Cobertura 3,85\%]

Referencia 2 - Cobertura 0,72\%

modelo de educación que se adapta a las capacidades de los alumnos

Referencia 3 - Cobertura 0,92\%

Aquella educación que trata por igual a todas las personas, sean como sean o tengan los problemas que tengan, recibiendo todos por igual, los mismos métodos de enseñanza y educación, partiendo de sus conocimientos previos.

Referencia 4 - Cobertura 1,10\%

Consiste en que a partir de metodologías y actividades específicas este todo dé resultados positivos

$\leq$ Elementos internos $\backslash$ Profesores $\backslash$ Pautas de intervención. Profes $>-\$ 7$ referencias codificadas [Cobertura 9,76\%]

Referencia 2 - Cobertura 2,33\%

En apoyo siempre se introducen cambios. Evaluación continua es tener en cuenta lo que saben

Referencia 3 - Cobertura 0,36\%

Autoevaluación

Referencia 4 - Cobertura 1,10\%

Evaluar los procesos no solo los resultados

Referencia 5 - Cobertura $0,56 \%$

Evaluación entre ellos

Referencia 6 - Cobertura 2,28\%

Repasar los exámenes con ellos para que ellos mismos analicen lo que han hecho bien y mal

Figura 10. Resultados obtenidos en el estudio 
$\leq$ Elementos internos $\backslash$ Profesores $\backslash$ Pautas de intervención. Profes $>-\$ 12$ referencias codificadas [Cobertura $17,50 \%$ ]

Referencia 9 - Cobertura 0,92\%

Revisión continúa de los aprendizajes

$\leq$ Elementos internos \Profesores\Transcripción grupo de discusión profesores $>-\S 42$ referencias codificadas [Cobertura 8,04\%]

Referencia 9 - Cobertura 0,09\%

Hombre pero la evaluación inicial sí que la haces en el aula.

Referencia 10 - Cobertura $0,06 \%$

vas adaptando esos conocimientos previos

Referencia 11 - Cobertura 0,20\%

estas actividades no las puede hacer asique le proporciono estas otras y estas que las pensaba hacer escritas se las voy hacer orales

Referencia 25 - Cobertura 0,23\%

cuando haces una evaluación en una clase sobre cualquier tema que hay luego se va a corregir eso pero en función de los errores y aprendas sobre ellos.

Referencia 26 - Cobertura $0,32 \%$

un niño que a lo mejor no ha sacado mucho más pero que ha tenido un esfuerzo yo tengo que valorar eso, entonces cuando pone "evaluar los logros de cada alumno" cada uno individualmente con sus características.

Referencia 31 - Cobertura 0,36\%

una alumna su examen está en el nivel de lo que está trabajando pero yo a ella no la voy a suspender porque no llega a lo de sexto, la voy a aprobar si lo que ha trabajado en el trimestre va acorde con el trabajo y con lo que ha conseguido

Referencia 36 - Cobertura $0,15 \%$

Pero tú partes de la evaluación inicial y vas a saber que niño evoluciona y que niño no evoluciona

Figura 11. Séptimo análisis de los resultados obtenidos en el estudio

Manifestaciones de una concepción educativa desde un marco teórico constructivistas se aprecian en la consideración de la diversidad determinada por la etiquetación de los individuos en función de sus características que se materializa en una atención específica fuera del aula con ciertos momentos compartidos en el aula ordinaria. Se contempla el derecho a la escolarización normalizada, pero con consideraciones extraordinarias. Desde esta perspectiva todavía consideran que las adaptaciones curriculares son responsabilidad del profesorado de Pedagogía Terapéutica.

Desde la perspectiva sociológica subjetivista, recogemos opiniones referidas a las familias como agentes participativos, pero no colaborativos, es decir hablan de una participación informativa y consultiva sin considerar imprescindible su cooperación y mantienen fuera de la consideración de comunidad educativa el entorno del Centro. La evolución hacia el 
subjetivismo podemos apreciarla también en manifestaciones sobre la necesidad de coordinación entre el profesorado y la transmisión entre docentes de pautas de intervención efectivas.

$\leq$ Elementos internos $\backslash$ Profesores $\backslash$ Definiciones EI. Profes $>-\$ 9$ referencias codificadas [Cobertura 9,51\%]

Referencia 4 - Cobertura 1,42\%

alumnos/as diferentes puedan hacer todas las actividades programadas adaptando éstas a sus características y/limitaciones.

Referencia 7 - Cobertura 0,90\%

adaptaciones al currículo general para que cualquier persona pueda acceder a él

$<$ Elementos internos \directores\Transcripción Grupo discusión directores > $\S 5$ referencias codificadas [Cobertura $0,74 \%$ ]

Referencia 4 - Cobertura 0,14\%

Ahora están, pero se actúa diferenciadamente, según el ritmo y el proceso

Referencia 5 - Cobertura 0,22\%

término de la atención a la diversidad, antes estaba muy arraigado en los problemas puntuales de ciertos chavales

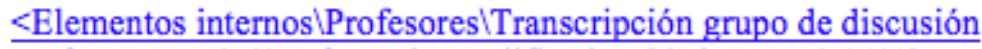
profesores $>-\S 42$ referencias codificadas [Cobertura $8,04 \%$ ]

Referencia 1 - Cobertura 0,22\%

Nosotros las ACS las seguimos haciendo los PT y los profesores en colaboración con el tutor pero sí que es verdad que la obligación es del tutor.

Referencia 2 - Cobertura 0,24\%

$\mathrm{O}$ viene el PT y te trae el cuadernito con el corta y pega preparado y tú lo vas preparando pero sigues estando en el aula pero no estas incluido, estas integrado.

Referencia 3 - Cobertura 0,33\%

Me parece totalmente inclusivo, me parece bien que un alumno que lo necesite salga a tener una atención especial y que luego entre y se dé un tipo de agrupamiento, unas veces tendrán que ser agrupamientos homogéneos...

Referencia 4 - Cobertura 0,15\%

A mí me parece que no tiene nada que ver que un marroquí no sepa español a que un autista no hable

Figura 12. Octavo análisis de los resultados obtenidos en el estudio 
<Elementos internos〈directores\Transcripción Grupo discusión directores>$\$ 10$ referencias codificadas [Cobertura 2,31\%]

\author{
Referencia 5 - Cobertura 0,34\% \\ Yo creo que la participación debe de ser más en la línea de información, \\ coordinación, etc. Yo no estoy muy segura de que haya que atender a otros \\ niveles de participación
}

Referencia 7 - Cobertura 0,23\%

El resto de participación creo que la estamos haciendo en todos los centros:

la informativa, la consultiva, etc.

$\leq$ Elementos internos $\backslash$ Profesores $\backslash$ Pautas de intervención. Profes $>-\S 12$ referencias codificadas [Cobertura $17,50 \%$ ]

Referencia 1 - Cobertura 2,05\%

Reuniones de coordinación con todos los profes que están en contacto con el niño

Referencia 2 - Cobertura 1,90\%

La última semana del trimestre se junta el profesor de apoyo con el tutor

Referencia 5 - Cobertura 2,77\%

Es bueno compartir aula con otros profesores, variar, cambiar impresiones hablar con ellos sobre los alumnos

\title{
Referencia 8 - Cobertura 2,38\% \\ En las reuniones de evaluación se habla de las necesidades o formas de trabajar de los niños
}

Referencia 11 - Cobertura 1,77\%

Sería ideal que la comunidad educativa participara dentro de un orden

Figura 13. Noveno análisis de los resultados obtenidos en el estudio

Es alentador comprobar, como ya expusimos anteriormente (Tabla2), que los resultados en el análisis de las alocuciones de los profesionales educativos, mayoritariamente se inclinan, al menos a nivel teórico y metateórico, por una concepción educativa comunicativosociocultural en base a una perspectiva sociológica dual. Es cierto que si nos basamos en el número de referencias (Tabla 2) sobre la práctica docente basada en metodologías socioculturales, la diferencia es menor respecto a las metodologías constructivistas y conductistas, pero de cualquier modo superior.

Planteamos a continuación las referencias que evidencian dichas posiciones de los docentes. Centramos el discurso en primer lugar en el análisis de las prácticas docentes aludiendo a las narraciones sobre metodología, programación y evaluación planteadas en los grupos de discusión, seguidamente, dentro de la concepción educativa tomaremos en consideración las opiniones referidas al concepto de diversidad, el progreso del alumnado, la consideración de los apoyos y el papel del docente. Finalizaremos el análisis con los resultados que hacen referencia a la perspectiva sociológica y el papel de la participación dentro de ella. 
$\leq$ Elementos internos \Profesores\Transcripción grupo de discusión profesores $>-\$ 42$ referencias codificadas [Cobertura $8,04 \%$ ]

Referencia 7 - Cobertura $0,11 \%$

Lo del personal docente, no docente, familias vale pero lo de los vecinos no

Referencia 8 - Cobertura 0,06\%

las familias sí que pueden intervenir

Referencia 14 - Cobertura $0,05 \%$

coordinación con el ciclo completo

Referencia 15 - Cobertura $0,09 \%$

Para la inclusión el tema de la coordinación me parece básico

Referencia 16 - Cobertura $0,23 \%$

fundamental para la inclusión de un alumno en un aula es la coordinación del tutor de ese aula y el PT o AL y con todos los que trabajen con ese niño.

Referencia 17 - Cobertura 0,11\%

problemática que tengan tus niños tienen que saberla todo el claustro

Referencia 18 - Cobertura 0,28\%

oyes decir que algunos utilizan esa forma de trabajar y parece que funciona y a lo mejor sí que será buen que de vez en cuando hubiera una reunión con todos los que están en contacto.

\section{Referencia 19 - Cobertura 0,13\%}

final de trimestre, la última semana e intentamos juntarnos con los profesores de apoyo

\section{Referencia 38 - Cobertura $0,15 \%$}

sí que se valora el colaborar con otros compañeros, el asesorar o el dar pautas de intervención.

\section{Referencia 39 - Cobertura $0,22 \%$}

Mejor que una crítica constructiva es mejor decir, pues, porque no utilizas esto que a mí me ha funcionado, es decir colaboración, dar pautas.

Figura 14. Décimo análisis de los resultados obtenidos en el estudio

Para dar coherencia y eficacia a las prácticas educativas transformadoras hacia la inclusión educativa plantean la necesidad de existencia de un discurso metodológico común en el centro que esté reflejado en el Proyecto Educativo de Centro. Hablan de metodologías basadas en aprendizaje cooperativo donde el trabajo por proyectos mediante la organización de grupos heterogéneos. Valoran positivamente la presencia de dos docentes por aula que facilite la utilización de nuevas técnicas mediante el aprovechamiento de los recursos existentes. 
$\leq$ Elementos internos $\backslash$ Profesores $\backslash$ Pautas de intervención. Profes $>-\$ 13$ referencias codificadas [Cobertura 21,50\%]

Referencia 1 - Cobertura 0,59\%

Aprendizaje cooperativo

Referencia 2 - Cobertura 1,72\%

Grupos heterogéneos en los que los alumnos puedan ayudarse entre sí

$\leq$ Elementos internos\directores\Transcripción Grupo discusión directores $>$ $\$ 19$ referencias codificadas [Cobertura $3,72 \%$ ]

Referencia 5 - Cobertura 0,14\%

habría que trabajar con técnicas y recursos diferentes a los que tenemos

Referencia 6 - Cobertura $0,12 \%$

a mí lo de dos profesores por aula me parece una buena idea.

$\leq$ Elementos internosldirectores\Transcripción Grupo discusión directores $>$ $\$ 19$ referencias codificadas [Cobertura $3,72 \%$ ]

Referencia 14 - Cobertura 0,11\%

para que sea inclusivo hablamos de metodología cooperativa

Referencia 15 - Cobertura 0,28\%

La metodología yo creo que tenemos que buscar que todos participen, que todos expongan, que participen todos para que nadie se sienta mal.

Referencia 17 - Cobertura 0,07\%

hace falta es unificar metodologías,

Referencia 18 - Cobertura 0,17\%

tiene que haber un discurso metodológico de centro establecido en el

proyecto educativo

Referencia 19 - Cobertura 0,19\%

decisiones metodológicas que tienen que ser en común son las que soportan principios educativos

Figura 15. Onceavo análisis de los resultados obtenidos en el estudio 
$\leq$ Elementos internos\Profesores\Transcripcion grupo de discusión profesores $>-\S 57$ referencias codificadas [Cobertura 9,58\%]

Referencia 10 - Cobertura $0,08 \%$

nos está funcionando muy bien el trabajo cooperativo.

Referencia 11 - Cobertura 0,09\%

los grupos cooperativos del tutor con los distintos profesores

Referencia 12 - Cobertura $0,28 \%$

grupos son heterogéneos poniendo a aquellos alumnos que tú crees que más puede

Referencia 14 - Cobertura 0,30\%

yo en esa clase concretamente entro al cooperativo para ver cómo funciona y este niño a la hora se ha transformado sobre todo de cómo funciona para relacionarse, que permite que el compañero le ayude,

Referencia 15 - Cobertura $0,12 \%$

A mí me parece que el trabajo con el cooperativo, las dinámicas de grupo, es bueno

Figura 16. Doceavo análisis de los resultados obtenidos en el estudio

$<$ Elementos internos\directores\Transcripción Grupo discusión directores> $\$ 19$ referencias codificadas [Cobertura 3,72\%]

Referencia 1 - Cobertura $0,10 \%$

si pones el mismo objetivo a todos, fracasarían.

Referencia 2 - Cobertura $0,33 \%$

objetivo común que aprendan a leer y a escribir, y a lo mejor a otro le conviene tener más unas habilidades sociales de desarrollo del día a día antes que leer o escribir

Referencia 3 - Cobertura $0,32 \%$

mirar la característica particular de cada niño, y a partir de ahí dar una respuesta para que cada niño adquiera lo que él pueda, sin poner un objetivo antes.

Referencia 4 - Cobertura 0,39\%

me gusta llamarlo intenciones educativas, que mis profesores me digan que intenciones tienen con cada niño, y eso es dar respuesta a sus necesidades y cada niño alcanzará unos niveles, unos objetivos

$\leq$ Elementos internos $\backslash$ Profesores $\backslash$ Pautas de intervención. Profes $>-\S 7$ referencias codificadas [Cobertura $11,68 \%$ ]

Referencia 1 - Cobertura 3,10\%

Partir de los intereses del niño. Realizar unidades didácticas de sus conocimientos previos. Construcción de aprendizajes

$\leq$ Elementos internos $\backslash$ Profesores $\backslash$ Pautas de intervención. Profes $>-\$ 7$ referencias codificadas [Cobertura $11,68 \%$ ]

Referencia 1 - Cobertura 3,10\%

Partir de los intereses del niño. Realizar unidades didácticas de sus conocimientos previos. Construcción de aprendizajes

$<$ Elementos internos \Profesores\Transcripcion grupo de discusión profesores $>-\S 57$ referencias codifiicadas [Cobertura 9,58\%]

Referencia 46 - Cobertura 0,28\%

no yo programo hasta que se lo que sabe el grupo-clase, no puedo empezar a hacer mi unidad didáctica hasta que no sé lo que saben, lo que les interesa. La unidad didáctica surge del momento

Referencia 47 - Cobertura $0,16 \%$

tengo que partir de la evaluación inicial de cada uno y de los intereses y pensar que unidad voy hacer porque

Figura 17. Treceavo análisis de los resultados obtenidos en el estudio 
A la hora de programar hablan de planificación centrada en la persona, con una intención educativa para cada alumno que permita dar respuesta a las necesidades individuales. El cambio mayor respecto a las otras metodologías es la necesidad de programar conociendo los destinatarios, sus conocimientos previos e intereses.

Respecto a la evaluación, se da mayor importancia a la participación del alumnado y la familia en el proceso con una aportación interesante centrada en la consideración de diferentes formas de evaluación en función de lo que se desee evaluar, contemplando la posibilidad de utilizar diferentes recursos comunicativos en el proceso: escrito, oral, gráfico, etc. Aceptando de esta manera la diversidad también en el momento de la evaluación.

$\leq$ Elementos internosldirectores $\backslash$ Transcripción Grupo discusión directores $>$ $\$ 1$ referencia codificada [Cobertura $0,23 \%]$

Referencia 1 - Cobertura 0,23\%

yo tuve un alumno que estuvo casi sin escolarizar y yo le hacía los exámenes orales porque de esa forma era muy bueno.

Referencia 10 - Cobertura 2,66\%

Utilizar cuando sea posible, diferentes medios de expresión en función de su motivación y funcionalidad.

Referencia 11 - Cobertura 1,15\%

Intentar que reflexionen sobre sus resultados

Referencia 12 - Cobertura 1,02\%

Evaluación por rúbricas (ap.cooperativo)

$\leq$ Elementos internos $\backslash$ Profesores $\backslash$ Transcripción grupo de discusión profesores $>-\S 15$ referencias codificadas [Cobertura 2,69\%]

Referencia 5 - Cobertura $0,17 \%$

Si porque ves que hay niños que en la clase normal no se expresan y en esos momentos son capaces de expresarse

Referencia 6 - Cobertura 0,18\%

rúbrica por ejemplo les ayuda mucho a ver muy detallado, a que se den cuenta lo que han hecho bien y lo que han hecho mal.

Referencia 7 - Cobertura $0,54 \%$

repase el examen con él, entonces yo hago una fotocopia y le volvemos a hacer y entonces yo creo que es de la forma que se da cuenta de lo que ha puesto y luego la tutora toma en cuenta que yo la diga pues es que en el examen se ha puesto súper nervioso pero sin decirle yo nada se ha dado cuenta de cosas que ha puesto mal, entonces yo sí que lo valoro

$\leq$ Elementos internos\directores\Transcripción Grupo discusión directores > $\$ 19$ referencias codificadas [Cobertura 3,72\%]

Referencia 10 - Cobertura $0,17 \%$

adecuación de las pruebas de evaluación respecto a lo que tú quieres evaluar realmente

Figura 18. Catorceavo análisis de los resultados obtenidos en el estudio 
$\leq$ Elementos internos \Profesores \Transcripción grupo de discusión profesores $>-\$ 57$ referencias codificadas [Cobertura 9,58\%]

Referencia 28 - Cobertura $0,26 \%$

¿Cuántas personas repiten la prueba de evaluación dos veces? Yo te la hago y te digo, aquí tienes que mejorar, aquí también y aquí también, hazlo y luego me lo devuelves

Referencia 29 - Cobertura 0,10\%

El trabajo cooperativo cuando ellos tienen que valorarse entre ellos

Referencia 30 - Cobertura $0,20 \%$

si vas por los grupos cuando están poniendo la puntuación de cómo cada uno ha hecho su trabajo son mucho más objetivos que nosotros.

Referencia 31 - Cobertura $0,15 \%$ los errores podrás mejorar pero si no eres consciente de lo que has hecho mal no vas a mejorar.

Referencia 34 - Cobertura 0,13\% una autoevaluación, no es fácil hacerlo en todo momento pero yo creo que es positiva.

Referencia 35 - Cobertura 0,08\%

A mí me gusta que vea el proceso y el razonamiento.

Referencia 36 - Cobertura 0,09\%

No evaluar tanto el resultado si no el proceso y la evolución.

Referencia 37 - Cobertura $0,12 \%$

También la tarea que hace en clase porque a lo mejor en el examen tiene mal día.

Referencia 38 - Cobertura 0,08\%

Valorando dependiendo de las características del alumno,

Referencia 39 - Cobertura 0,07\%

Valorarlo de acuerdo a su adaptación curricular.

Referencia 40 - Cobertura 0,19\%

Los compañeros saben que tiene su examen adaptado y lo aceptan y ya está y las notas

Referencia 41 - Cobertura $0,21 \%$

Intentamos que todo lo hagan, adaptado a su nivel y los compañeros ni se fijan si hacen otras cosas y las notas van en relación a ello.

Figura 19. Quinceavo análisis de los resultados obtenidos en el estudio

Desde una concepción educativa comunicativo-sociocultural, consideran la atención a la diversidad como elemento fundamental para hablar de inclusión. Parten de la noción de que todos somos diferentes y normalizan y valoran esta diferencia hasta el punto de considerar la necesidad de partir del conocimiento de las diferencias individuales para ofrecer a cada alumno lo que necesita. Muestran un concepto amplio de diversidad donde lo diferente se 
asuma de manera igualitaria desde el respeto y la solidaridad. La atención a la diversidad no está protagonizada por la discapacidad.

$\leq$ Elementos internos $\backslash$ Profesores $\backslash$ Pautas de intervención. Profes $>-\S 13$ referencias codificadas [Cobertura $21,50 \%$ ]

Referencia 13 - Cobertura 2,20\%

Evitar la sobreprotección de los propios compañeros hacia el alumnado con discapacidad

$\leq$ Elementos internos \Profesores $\backslash$ Transcripción grupo de discusión profesores $>-\S 15$ referencias codificadas [Cobertura 2,69\%]

Referencia 2 - Cobertura $0,19 \%$

cada niño tiene un rol distinto, cada uno tiene una función concreta que dentro de su grupo pequeño se van cambiando entre ellos

$\leq$ Elementos internos $\backslash$ directores $\backslash$ Definiciones EI directores. $>-\$ 7$ referencias codificadas [Cobertura 10,85\%]

Referencia 1 - Cobertura 0,92\%

Partir de sus intereses y necesidades y hacerlos extensivos a la educación de todos.

Referencia 2 - Cobertura 1,30\%

Que los alumnos diferentes puedan hacer todas las actividades programadas adaptando éstas a sus características o limitaciones.

$\leq$ Elementos internos $\backslash$ Profesores $\backslash$ Pautas de intervención. Profes $>-\$ 7$ referencias codificadas [Cobertura 11,68\%]

Referencia 6 - Cobertura 2,61\%

Hacer a todo el alumnado partícipes de la presencia del alumnado con necesidades educativas especiales

$\leq$ Elementos internos $\backslash$ Profesores $\backslash$ Transcripcion grupo de discusión profesores $>-\$ 57$ referencias codificadas [Cobertura 9,58\%]

Referencia 1 - Cobertura 0,28\%

Facilitar la integración en el aula de todo el alumnado con necesidad de apoyo específico aceptando y respetando sus características personales, sociales y culturales.

Referencia 2 - Cobertura $0,17 \%$

Atención a la diversidad y a las necesidades del alumnado, me parece que la inclusión es un signo de calidad.

Figura 20. Dieciseisavo análisis de los resultados obtenidos en el estudio 
$\leq$ Elementos internos \Profesores $\backslash$ Transcripción grupo de discusión profesores $>-\$ 57$ referencias codificadas [Cobertura 9,58\%]

Referencia 17 - Cobertura $0,16 \%$

genera una actitud positiva, no siempre en la vida vas a estar con alguien del que puedas sacar provecho

Referencia 18 - Cobertura $0,12 \%$ generar esa actitud respecto al que necesita la ayuda, no al que da la ayuda.

Referencia 19 - Cobertura $0,12 \%$

También hablarle de las diferencias de cada niño, concienciarles, sensibilizarles.

Referencia 22 - Cobertura $0,22 \%$

Tener presente alumnado con necesidades educativas especiales en el aula mejora en el resto de los estudiantes la comprensión de la diversidad.

Referencia 51 - Cobertura $0,26 \%$ niños que iban con bombas de oxígeno y tenías que explicarles que eso no se toca, que eso es para él, dejárselo tocar a todos un día, que pierdan el interés y luego trabajar

Referencia 52 - Cobertura $0,12 \%$ tienen que conocerlo y conocer sus limitaciones y ver hasta dónde pueden llegar.

Referencia 53 - Cobertura $0,17 \%$ no está recogido el beneficio que supone para el resto del grupo la presencia del niño con necesidades especiales

$\leq$ Elementos internos $\backslash$ directores $\backslash$ Definiciones EI directores. $>-\$ 19$ referencias codificadas [Cobertura 16,23\%]

Referencia 15 - Cobertura 2,05\%

Aquella en la que no existen diferencias entre los alumnos dentro de las aulas, es decir, existe respeto, aceptación compañerismo solidaridad entre compañeros. Incluye a toda la comunidad

Figura 21. Diecisieteavo análisis de los resultados obtenidos en el estudio

Hablan de progreso como concepto educativo que implica el desarrollo personal de todos los individuos a lo largo de la vida. Debe comportar una educación eficaz y de calidad donde el éxito sea responsabilidad de todos y para todos. 
$\leq$ Elementos internos $\backslash$ directores $\backslash$ Definiciones EI directores. $>-\$ 7$ referencias codificadas [Cobertura 10,85\%]

\section{Referencia 4 - Cobertura 2,77\%}

Facilitar, integrar e implicar a las personas con alguna dificultad dentro de un mismo contexto escolar, sin marginación ni exclusión por parte de todos los agentes de la comunidad educativa, facilitando y ayudándoles en su desarrollo personal y social.

\section{Referencia 5 - Cobertura 0,87\%}

adaptaciones al currículo general para que cualquier persona pueda acceder a él

Referencia 6 - Cobertura 0,59\%

Consiste en que todos los alumnos, dando igual su raza, sexo o condición sean partícipes o deban ser partícipes en el proceso de enseñanzaaprendizaje.

\section{Referencia 7 - Cobertura 1,80\%}

buenas relaciones entre todos dando lugar a un clima bueno del aula y donde se dé un aprendizaje eficaz, e igual para todos, adaptado a las necesidades de cada uno.

$\leq$ Elementos internos $\backslash$ Profesores $\backslash$ Definiciones EI. Profes $>-\$ 4$ referencias codificadas [Cobertura 6,00\%]

Referencia 2 - Cobertura 1,80\% todos los alumnos puedan desarrollarse y educarse de modo favorable y de manera integrada en el aula, independientemente de sus características individuales.

$\leq$ Elementos internos $\backslash$ Profesores $\backslash$ Transcripcion grupo de discusión profesores $>-\$ 57$ referencias codificadas [Cobertura 9,58\%]

Referencia 2 - Cobertura 0,17\%

Atención a la diversidad y a las necesidades del alumnado, me parece que la inclusión es un signo de calidad.

Figura 22. Dieciochoavo análisis de los resultados obtenidos en el estudio

$\leq$ Elementos internos $\backslash$ Profesores $\backslash$ Pautas de intervención. Profes $>-\S 13$ referencias codificadas [Cobertura 21,50\%]

Referencia 4 - Cobertura 1,74\%

$\mathrm{El}$ apoyo mutuo en ocasiones funciona mejor que el apoyo del profesor

Referencia 5 - Cobertura 1,41\%

A veces ellos mismos crean la dificultad y la resuelven

Figura 23. Diecinueveavo análisis de los resultados obtenidos en el estudio 
Los apoyos ya no son destinados a unos pocos. Consideran que todos podemos ser objeto de los mismos en determinadas ocasiones, así mismo contemplan una nueva consideración del apoyo, constituida por los propios compañeros.

$\leq$ Elementos internos $\backslash$ Profesores $\backslash$ Pautas de intervención. Profes $>-\S 13$ referencias codificadas [Cobertura $21,50 \%$ ]

Referencia 4 - Cobertura 1,74\%

$\mathrm{El}$ apoyo mutuo en ocasiones funciona mejor que el apoyo del profesor

Referencia 5 - Cobertura 1,41\%

A veces ellos mismos crean la dificultad y la resuelven

Figura 24. Veinteavo análisis de los resultados obtenidos en el estudio

Los propios docentes se ven impulsores del cambio. Manifiestan la necesidad de obtener una formación específica en los centros que fomente la creación de una sociedad inclusiva. Desde esta concepción educativa sí tienen consideración la crítica constructiva entre los docentes.

$\leq$ Elementos internos $\backslash$ Profesores $\backslash$ Transcripción grupo de discusión profesores $>-\S 15$ referencias codificadas [Cobertura 2,69\%]

Referencia 10 - Cobertura $0,07 \%$

A mí la crítica constructiva no me parece mal.

$\leq$ Elementos internos\directores\Transcripción Grupo discusión directores $>$ $\$ 19$ referencias codificadas [Cobertura 3,72\%]

Referencia 8 - Cobertura $0,18 \%$

tenía que existir una formación específica para cada centro, porque cada centro es diferente

Figura 25. Veintiunavo análisis de los resultados obtenidos en el estudio

Uno de los cambios más importantes a considerar desde la perspectiva sociológica dual es la ampliación del término participación considerada como convivencia, implicando acuerdo, sociedad, comunidad y solidaridad. Desde esta perspectiva la Educación Inclusiva discurre como un derecho que implica formar parte de una comunidad inclusiva donde la participación real de la comunidad se traduce en tomar decisiones consensuadas. Dan importancia al desarrollo de la inteligencia emocional mediante el trabajo de habilidades sociales que faciliten la expresión de emociones y favorezca la cohesión social. Creen que los aprendizajes se realizan desde la convivencia en grupo y la utilización de los recursos de la comunidad que fomenten su generalización. Para ello es necesario buscar metodologías que promuevan la participación de todos estableciendo cauces para que las familias formen parte del sistema. Hay que crear proyectos en común. Los docentes manifiestan la necesidad de lograr la conexión entre escuela y universidad. 
$\leq$ Elementos internos $\backslash$ Profesores $\backslash$ Pautas de intervención. Profes $>-\$ 13$ referencias codificadas [Cobertura 21,50\%]

Referencia 6 - Cobertura $0,77 \%$

Deben manifestar sus emociones

Referencia 7 - Cobertura 2,46

Importante tener programadas actividades que fomenten las relaciones positivas entre el alumnado

Referencia 8 - Cobertura 1,15\%

Desarrollar programas de habilidades sociales

$\leq$ Elementos internos \Profesores \Transcripción grupo de discusión profesores $>-\S 15$ referencias codificadas [Cobertura 2,69\%]

Referencia 11 - Cobertura 0,11\%

Yo utilizo Los recursos de la comunidad para generalizar los aprendizajes.

Referencia 12 - Cobertura 0,19\%

la comunidad educativa participa activamente en los programas del centro y pone a su disposición los recursos porque colabora.

Referencia 14 - Cobertura 0,06\%

colaboramos con todas las asociaciones

Referencia 15 - Cobertura $0,06 \%$

pedir a los padres que también participen,

$\leq$ Elementos internos\directores\Transcripción Grupo discusión directores> $\$ 19$ referencias codificadas [Cobertura 3,72\%]

Referencia 9 - Cobertura 0,41\%

La escuela de educación lo que tendría que asumir es la base y luego en cada lugar según las necesidades tener una forma de profundización e ir en concreto a donde está la forma, el pensar, las ideas, etc.

Referencia 11 - Cobertura $0,15 \%$

Los padres un día se reúnen en el comedor y valoran la actuación del centro.

Referencia 12 - Cobertura 0,14\%

metodología por proyectos y como no participen las familias estás perdido

Referencia 13 - Cobertura 0,11\%

los padres también tienen que participar en la escuela

Figura 26. Veintidosavo análisis de los resultados obtenidos en el estudio 
$\leq$ Elementos internos \Profesores $\backslash$ Transcripción grupo de discusión profesores $>-\S 57$ referencias codificadas [Cobertura 9,58\%]

Referencia 8 - Cobertura $0,06 \%$ abarcar un poco toda la comunidad educativa

Referencia 9 - Cobertura 0,07\%

Porque toda la comunidad tiene que estar inmersa.

$\leq$ Elementos internos $\backslash$ directores $\backslash$ Definiciones EI directores. $>-\$ 19$ referencias codificadas [Cobertura 16,23\%]

Referencia 2 - Cobertura 0,49\%

derecho todos alumnos estar en aula normalizada.

Referencia 3 - Cobertura 0,35\%

Estar escolarizado como uno más

Referencia 5 - Cobertura 0,85\%

educación que realmente acoge a todas las personas física y

participativamente

$\leq$ Elementos internos \Profesores $\backslash$ Transcripción grupo de discusión profesores $>-\$ 57$ referencias codificadas [Cobertura 9,58\%]

Referencia 14 - Cobertura $0,14 \%$

educación emocional que creo que es una asignatura pendiente para todos me parece importantísimo

Referencia 21 - Cobertura 0,06\%

inteligencia emocional es importante.

Referencia 22 - Cobertura $0,22 \%$

control emocional muchas veces hace que con el tiempo puedan aprender a comunicarse de otra manera, de ser consciente de que me enfada y de que no

Referencia 23 - Cobertura 0,10\%

educación emocional va un poco más allá de las habilidades sociales.

Referencia 24 - Cobertura 0,09\%

se está empezando a trabajar interioridad y también les ayuda

Figura 27. Veintitresavo análisis de los resultados obtenidos en el estudio 
$\leq$ Elementos internos $\backslash$ directores $\backslash$ Definiciones EI directores. $>-\$ 19$ referencias codificadas [Cobertura 16,23\%]

Referencia 17 - Cobertura 1,20\% integración y participación de todos los miembros de la comunidad educativa, así como familias, entorno, etc

$\leq$ Elementos internos\directores\Transcripción Grupo discusión directores> $\$ 34$ referencias codificadas [Cobertura 7,62\%]

Referencia 19 - Cobertura $0,44 \%$ el centro tiene que ser inclusivo, todas las decisiones tienen que ser inclusivas, todo el ambiente tiene que serlo, y eso lo propiciamos nosotros, incluyendo las relaciones del claustro, las asociaciones con los padres, etc

Referencia 20 - Cobertura $0,10 \%$

Educar a la comunidad propia también es inclusivo

Referencia 27 - Cobertura $0,13 \%$

Las familias son esenciales en la educación, porque es la clave.

Referencia 28 - Cobertura $0,14 \%$

Hay que buscar un cauce para que los padres también entren en el sistema

Referencia 29 - Cobertura 0,17\%

Cuando las familias entren y todos vayamos en común hacia lo mismo, la cosa mejora

Referencia 30 - Cobertura 0,17\%

la idea es que la comunidad fabrique su propio proyecto educativo, cada uno en su medida

Referencia 31 - Cobertura 0,39\%

si eso se conforma en documentos de centro y se tiene a la comunidad como galante de ese proyecto entonces es cuando tira para delante y donde empiezan a sentarse realmente los valores como inclusión

Referencia 33 - Cobertura 0,41\% está muy des conexionada de la escuela la universidad y sobre todo la educación y las escuelas que deben estar intimamente relacionada y sabemos que a la gente no le interesa, no le interesa a la universidad

Referencia 34 - Cobertura $0,14 \%$ es una gozada ver que alguien se interesa por nosotros y por los niños.

Figura 28. Veinticuatroavo análisis de los resultados obtenidos en el estudio

\section{Discusión y conclusiones}

En general podemos decir que los docentes a pesar de mostrar una actitud positiva hacia la filosofía inclusiva, dado que la consideran una práctica justa respaldada por un derecho, pero no se sienten con formación suficiente, así como recursos y apoyos necesarios para 
ofrecer una atención adecuada. Estas mismas conclusiones se obtuvieron en una investigación dirigida por Cardona de la Universidad de Alicante (Chiner-Sanz, 2011). Estos resultados son igualmente coincidentes en la manifestación de falta de tiempo para atender adecuadamente las diferencias del alumnado.

Sí podemos apreciar diferentes interpretaciones en función del rol profesional que están desempeñando. Los maestros entienden la inclusión como un tipo de educación que intenta proporcionar igualdad de oportunidades (a nivel práctico y a nivel emocional); también en su lenguaje se observa que lo consideran un derecho legal, aunque eso parece ser respondido desde el discurso social aprendido. La idea más recurrente es la de dar oportunidades de aprendizaje individualizadas. Los profesores al trabajar de forma más cercana al alumno, se sienten más próximos a sus necesidades emocionales. El imaginario común de este colectivo se acerca más al mundo emocional que el de directores que han interiorizado el rol de gestores que miran por el bienestar común. Los directores en sus definiciones manifiestan una línea común que consiste en tener en cuenta los aspectos contextuales que incluyen en la E.I. Las palabras más usadas tienen que ver con la participación, programación, espacios, las demandas de la inspección como (programación, convivencia), lo que puede poner en marcha funcionamientos profesionales ligados a la burocracia y desligados de las sensibilidades personales... A diferencia de los profesores, que usan más palabras referidas a individualidad, mecanismos, herramientas. Con esto queremos decir que a los profesores dentro de la E.I. les interesa más, las herramientas, las estrategias, recursos y mecanismos para dar respuestas individuales, mientras que los directores orientan más el concepto E.I. como algo global, contextual, dependiente del colectivo. De todo esto deducimos la importancia de que todos los profesionales de la educación pasen por diferentes roles a lo largo de su trayectoria profesional para adquirir una visión más profunda de la educación.

Existe una evolución hacia metodologías constructivistas relacionadas con la utilización de estrategias de enseñanza y formas de evaluación de los aprendizajes con una evaluación inicial, procesual y final, pero no se observa el paso hacia metodologías socioculturales en las que las estrategias de agrupamiento cumplen una función crítica.

Manifiestan la necesidad de un liderazgo participativo que sirva de motor de la escuela reflejado en el Proyecto educativo de Centro. Hablan, pero desde un plano teórico de la importancia de la coordinación y colaboración entre profesionales y familias, pero al mismo tiempo exteriorizan prácticas contrapuestas.

Muestran recelo hacia la reflexión y el análisis de sus propias prácticas educativas, elemento fundamental para el desarrollo profesional y la mejora de la enseñanza.

El profesorado justifica su escaso uso de metodologías y prácticas inclusivas en la oposición que muestran las familias hacia este tipo de estrategias que pueden comprometer la educación de sus hijos. Farrell (2000b) analiza los factores que pueden afectar las actitudes de las familias hacia la inclusión y concluye que cuando se les informa y sensibiliza sobre todas sus implicaciones, se produce un efecto positivo dirigido hacia la consideración de la mejora del desarrollo personal y social de sus hijos.

La mayor presencia de referencias a la variable presencia y participación en las definiciones que dan los directores, frente a alusiones vinculadas al progreso o aprendizaje del alumnado, podemos interpretarlo como la predisposición real que tienen en liderar procesos inclusivos, unido por otro lado a la consideración de falta de efectividad que la llamada educación inclusiva tiene aún hoy en día, respecto a los logros académicos del alumnado con ACNEAE. La variación de estas referencias en el grupo de profesores, con una mayor incidencia de alusiones referidas al progreso del alumnado frente a la 
participación, pone de manifiesto la preocupación por el logro de competencias y destrezas que el docente persigue en su práctica diaria, y de aquí podemos concluir y comprender la dificultad por comprometerse en desarrollar prácticas inclusivas eficaces que suponen un trabajo adicional no respaldado por habilidades y recursos necesarios para ofrecer calidad educativa. Similares conclusiones las hallamos en diferentes estudios realizados por Cardona (2000) con 115 profesores de la provincia de Alicante; Alemany yVilluendas (2004) en Melilla; Álvarez, Castro, Campo, y Álvarez (2005) con una muestra de 389 docentes del Principado de Asturias

Las creencias epistemológicas en las que el profesorado basa su perspectiva sociológica, influyen de una manera directa con la forma de entender la discapacidad: desde una perspectiva sistémico-estructuralista es considerada como algo inherente al alumno, lo que desvincula al docente de su intervención; hasta una visión dual que considera que las dificultades que pueda plantear un alumno son fruto de la interacción de éste con el ambiente de aprendizaje.

En definitiva, podemos concluir que la falta de formación y de apoyos y recursos tanto personales como materiales y temporales, provoca en el profesorado una falta de interés y rechazo hacia un cambio de actitud que revalorice sus sentimientos de competencia hacia el logro de una verdadera educación inclusiva. Un estudio realizado por Jiménez, Díaz y Carballo (2006) cifran en un $57.8 \%$ el profesorado que no se considera bien preparado para atender a la diversidad.

Hemos constatado que los profesores apoyan el concepto general de inclusión, pero que hacerla realidad es todavía un proyecto. Esta misma conclusión es apoyada por diferentes investigaciones internacionales (Scruggs y Matropieri, 1996; Avramidis y Norwich, 2001; Avramidis, y Kalyva, 2007). En todos estos estudios cuando se pregunta al profesorado sobre cómo poner en práctica estrategias inclusivas, muestran una actitud conservadora basada en un concepto de educación objetivista en la que el alumnado con necesidades específicas de apoyo educativo debe seguir recibiendo atención por parte de profesionales especialistas en entornos restrictivos.

\section{Referencias}

Ainscow, M. (2001). Desarrollo de escuelas inclusivas: ideas, propuestas y experiencias para mejorar las instituciones escolares. Madrid: Narcea

Ainscow, M., Farrell, P., y Tweddle, D. (2000). Developing policies for inclusive education: a study of the role of local education authorities. International journal of inclusive education, 4(3), 211-229.

Ainscow, M., Booth, T., y Dyson, A. (2006). Improving schools, developing inclusion. London: Routledge.

Alemany, I., y Villuendas, M.D. (2004). Las actitudes del profesorado hacia el alumnado con necesidades educativas especiales. Convergencia. Revista de Ciencias Sociales, 11(34), 183-215.

Althusser, L. (1970). Idéologie et appareils idéoligiques d’État: sur la reproduction des conditions de production. La Pensée, 3-21.

Álvarez, M., Castro, P., Campo, M.A., y Álvarez, E. (2005). Actitudes de los maestros ante las necesidades educativas específicas. Psicothema, 17(4), 601-606.

Avramidis, E., y Kalyva, E. (2007). The influence of teaching experience and professional developmente on Greek teachers' attitudes towards inclusion. European Journal of Special Needs Education, 22(4), 367-389. 
Avramidis, E. y Norwich, B. (2001). Teachers' attitudes towards integration/inclusion: a review of the literature. European Journal of Special Needs Education, 17(2), 129-147.

Beck, U., Lash, S., y Giddens, A. (1997). Modernización reflexiva: política, tradición y estética en el orden social moderno. Alianza Editorial.

Berger, P. L., y Luckmann, T., (1968). La construcción social de la realidad. Buenos Aires: Amorrortu.

Bourdieu, P. y Passeron, J.C. (1970). La reproduction: éléments pour une téorie de système d'enseignement. Paris: Les Éditions de Minuit.

Bruner, J.S. (2000). La educación, puerta de la cultura. Madrid: Visor.

Bunch, G. (2015). Un análisis del movimiento de la Educación Inclusiva en Canadá. Cómo trabajar. Revista Electrónica Interuniversitaria de Formación del Profesorado, 18 (1), 115. doi: http://dx.doi.org/10.6018/reifop.18.1.214311

Carr, W., y Kemmis, S. (1988). Teoría crítica de la enseñanza. Barcelona: Martínez Roca.

Cardona, M.C. (2000). Regular classroom teachers' perceptions of inclusion: implication for teachers' preparation programs in Spain. En D. Day y D. Veen (Eds.), Educational research in Europe (pp. 37-47). Lovaina: Garant y European Educational Research Association.

Cascante, C. (1995). Los ámbitos de decisión de la práctica educativa. En Cascante, C. Proyecto docente de Didáctica general. Universidad de Oviedo, (pp. 442-449).

Chiner-Sanz, E. (2011). Las percepciones y actitudes del profesorado hacia la inclusión del alumnado con necesidades educativas especiales como indicadores del uso de prácticas educativas inclusivas en el aula. Universidad de Alicante.

Commision for Racial Equality. (2001). Statutory Code of Practice on the Duty to Promote Race Equality. (Consultation Draft). London: CRE.

De la Rosa, L. (2017). Objetos convertidos en sujetos: encuentros con voces excluídas dentro de una asignatura sobre inclusión educativa. Revista Electrónica Interuniversitaria de Formación del Profesorado, 20(3), 209-223. doi: http://dx.doi.org/10.6018/reifop.20.3.260111

Department for Education and Skills U K, (2001). Inclusive Schooling. Children with Special Educational Needs. London: DfES Publications.

Disability Rights Commission, (2007). Disability Rights Commission annual report and accounts 2006 to 2007. London: DfES Publications.

Dyson, A., y Millward, A. (2000). Schools and special needs: Issues of innovation and inclusion. Sage.

Echeíta, G. y Ainscow, M. (2011). La educación inclusiva como derecho marco de referencia y pautas de acción para el desarrollo de una revolución pendiente. Tejuelo: Didáctica de la Lengua y la Literatura. Educación, 12, 26-46.

Echeíta, G., y Verdugo, M. Á. (2004). La declaración de Salamanca sobre necesidades educativas especiales 10 años después: Valoración y prospectiva. Salamanca: Publicaciones INICO.

Echeíta, G., Verdugo, M. A., Sandoval, M., Calvo, I., y González-Gil, F. (2009). Paradojas y dilemas en el proceso de inclusión educativa en España. Revista de Educación, 349, 153-178.

Farrell, P. (2000a). International Developments in Curriculum Innovations for Pupils with Learning Difficulties. International Special Education Congress 2000. University of Manchester, UK.

Farrell, P. (2000b). The impact of research on developments in inclusive education. International Journal of Inclusive Education, 4(2), 153-162.

Flecha, R., Gómez, J., y Puigvert, L. (2001). Teoría sociológica contemporánea. Barcelona. Paidós.

Freire, P. (1970). Pedagogía del oprimido. México: Siglo XXI. 
Giddens, A. (1995). Modernidad e identidad del yo. Barcelona: Península.

Giddens, A. (1998). La constitución de la sociedad. Bases para la teoría de la estructuralización. Buenos Aires: Amorrortu.

Habermas, J. (2001a). Teoría de la acción comunicativa. Racionalidad de la acción. Madrid: Taurus

Habermas, J. (2001b). Teoría de la acción comunicativa. Crítica de la razón funcionalista. Madrid: Taurus.

Herreras, E. B. (2004). Una herramienta al servicio de perfeccionamiento docente: NUD* IST VIVO. Revista de Informática Educativa y Medios Audiovisuales, 1(3), 21-27.

Jiménez, M.A., Díaz, M.T., y Carballo, R. (2006). Respuesta educativa a la diversidad desde la perspectiva del profesorado de la ESO: Estudio en la Comunidad Autónoma de La Rioja. Contextos educativos, 8(9), 33-50.

Krueger, R. A. (1991). Focus groups: A practical guide for applied research. Beverly Hills, CA: Sage.

Krueger R. A., y Casey, M. A. (2000). Focus Group a practical guide for applied research (3th Ed.). Thousand Oaks, CA: Sage.

Merton, R., y Kendall, P. (1946). The Focused Interview. The American Journal of Sociology, 51(6), 541-557.

Mitchell, D. (2005). Contextualizing Inclusive Education: Evaluating Old and New International Paradigms. Londres: Routledge.

Parrilla, A. \& Sierra, S. (2015). Construyendo una investigación inclusiva en torno a las distintas transiciones educativas. Revista Electrónica Interuniversitaria de Formación del Profesorado, 18 (1), 161-175.

Piaget, J., y Bringuier, J. C. (1977). Conversaciones con Jean Piaget. Barcelona: Granico.

Rogoff, B. (1993). Aprendices del pensamiento. El desarrollo cognitivo en el contexto social. Barcelona: Paidós.

Sebba, J. y Ainscow, M. (1996). International developments in inclusive schooling: Mapping the questions. Cambridge Journal of Education, 26(1), 5-18.

Scruggs, T.E., y Matropieri, M.A. (1996). Teacher perceptions of mainstreaming/inclusion, 1958-1995: A research synthesis. Exceptional Children, 63(1), 59-74.

UNESCO. (1994). Declaración de Salamanca y Marco de Acción sobre necesidades educativas especiales. UNESCO.

UNESCO. (2005). Guidelines for inclusión: ensuring access to education for all. Paris. Unesco. Recuperado el 08 de marzo de 2017 desde http://www.unesco.org/education/inclusive.

Vislie, L. (2003). From integration to inclusion: focusing global trends and changes in the western European societies. European Journal of Special Needs Education, 18(1), 1735.

Vygotsky, L.S. (1995). Pensamiento y lenguaje. Barcelona: Paidós.

Vygotsky, L.S. (1996). El desarrollo de los procesos psicológicos superiores. Barcelona: Crítica. Wells, G. (2001). Indagación dialógica. Barcelona: Paidós.

Wood, D., Bruner, J. S., y Ross, G. (1976). The role of tutoring in problem solving. Journal of child psychology and psychiatry, 17(2), 89-100. 